Maloprim by the patient had near fatal results. Pyrimethamine was taken by all four patients, suggesting that this may have been the toxic agent.

Previous workers assumed that the sulphonamide component of Fansidar was responsible for the pulmonary toxicity..$^{1-5}$ In one report a lymphocyte transformation test yielded positive results in the presence of sulfadoxine but also with pyrimethamine, perhaps suggesting that non-specific cell activation had occurred. ${ }^{3}$ We were unable to show lymphocyte activation with either dapsone or pyrimethamine, but this was assessed in only one patient and then only after she had recovered and taken steroids. Dapsone, the other constituent of Maloprim, is structurally related to the sulphonamides. Nevertheless, despite its widespread use it has not been reported to cause pulmonary eosinophilia. Similarly there are no reports of pulmonary toxicity with chloroquine. Three further cases of pulmonary eosinophilia, one confirmed by lung biopsy, have been reported to Wellcome Research Laboratories in patients who had taken Maloprim, and two cases of pulmonary toxicity with systemic features have been reported in patients who had taken pyrimethamine-chloroquine ( $\mathrm{L}$ Maskell, personal communication). We therefore believe that pyrimethamine may cause pulmonary eosinophilia.

We thank Dr W D Riding and Dr J O Hunter for permission to report cases 3 and $4 ; \mathrm{Mr} M \mathrm{~V}$ Braimbridge for obtaining the lung biopsy specimens; Dr L Delgardo for performing the lymphocyte transformation test; and $\mathrm{Dr}$ D B A Hutchinson, Wellcome Research Laboratories, for supplying Maloprim. Daraclor is no longer available in the United Kingdom.

1 Whitfield $\mathrm{D}$. Presumptive fatality due to pyrimethamine-sulfadoxine, Lance 1982;ii: 1272 .

2 Svanbom M, Rombo L, Gustafsson L. Unusual pulmonary reaction during short term prophylaxis with pyrimethamine-sulfadoxine (Fansidar). BrMed F 1984;288:1876.

3 Buser $P$, Raber J. Eosinophilic pulmonary infiltrate during anti-malarial chemoprophylaxis with Fansidar. Swiss Medical fournal 1985;115:1174-6.

4 Murphy RL, Phair JP. Systemic reaction to pyrimethamine-sulfadoxine. $f$ Fam Pract 1986;22:375-6.

5 McCormack D, Morgan WKC. Fansidar hypersensitivity pneumonitis. $\mathrm{Br} \mathcal{F}$ Dis Chest 1987;81:194-6.

(Accepted 10 August 1988)

\section{Plasma methionine enkephalin concentration and prognosis in primary biliary cirrhosis}

\section{J R Thornton, M S Losowsky}

Department of Medicine, St James's University Hospital, Leeds LS9 7TF J R Thornton, MRCP, lecturer M S Losowsky, FRCP, professor

Correspondence to: $\mathrm{Dr}$ Thornton.
Plasma methionine enkephalin concentration is increased in patients with cirrhosis and ascites but is often normal in patients with compensated cirrhosis without ascites.' It may, therefore, reflect the severity and prognosis of the cirrhosis. We measured plasma methionine enkephalin concentrations in 34 patients with primary biliary cirrhosis of various stages of severity and monitored the clinical course of the disease.

\section{Patients, methods, and results}

We diagnosed primary biliary cirrhosis on the basis of the clinical presentation and results of histological examination of the liver. Mitochondrial antibodies $(>1 / 100)$ were present in 28 patients.

We collected venous blood samples and measured concentrations of methionine enkephalin by radioimmunoassay (Immuno Nuclear; Stillwater, Minnesota). ${ }^{1}$ The assay was unaffected by addition of bilirubin. Concentrations of bilirubin, albumin, and creatinine and activities of alkaline phosphatase and alanine aminotransferase were measured in aliquots of the same samples. Samples were taken from all patients at the start of the study; a second sample was taken from all the patients except one, who died two months after the start of the study, and a third sample was taken from three patients. We monitored the clinical progression of the disease for 15 months or until death.

At the start of the study the plasma methionine enkephalin concentration (median 160 (range 50-1310) $\mathrm{pmol} / \mathrm{l})$ was significantly increased $(\mathrm{p}<0.001$, MannWhitney U test) compared with the concentration that we had found in healthy people $(65(50-95) \mathrm{pmol} / \mathrm{l})$ and in patients with other diseases $(73(50-110) \mathrm{pmol} / \mathrm{l})$ in a previous study.' Median (range) values (and the limits of normal) of other plasma measurements in this study were: bilirubin 28 (8-367) $\mu \mathrm{mol} / \mathrm{l}$ (3-15 $\mu \mathrm{mol} / \mathrm{l})$; alkaline phosphatase 357 (147-1274) IU/l (21-91 IU/I); alanine aminotransferase 64 (21-169) IU/1 (0-35 IU/l); albumin $37(26-45) \mathrm{g} / \mathrm{l}(37-49 \mathrm{~g} / \mathrm{l})$; and creatinine $75(47-186) \mu \mathrm{mol} / \mathrm{l}(45-120 \mu \mathrm{mol} / \mathrm{l})$.

Spearman's rank correlation showed that methionine enkephalin concentration was significantly correlated with bilirubin concentration $(r=0.738$, $\mathrm{p}<0.001)$, alkaline phosphatase activity $(\mathrm{r}=0.492$, $\mathrm{p}<0.005$ ), and plasma albumin concentration $(\mathrm{r}=$ $-0.455, \mathrm{p}<0.01)$ but not with alanine aminotransferase activity or plasma creatinine concentration.

Seven patients died a median of 10 months (range 2-13 months) after the start of the study (figure). Three died from renal failure with ascites that was resistant to

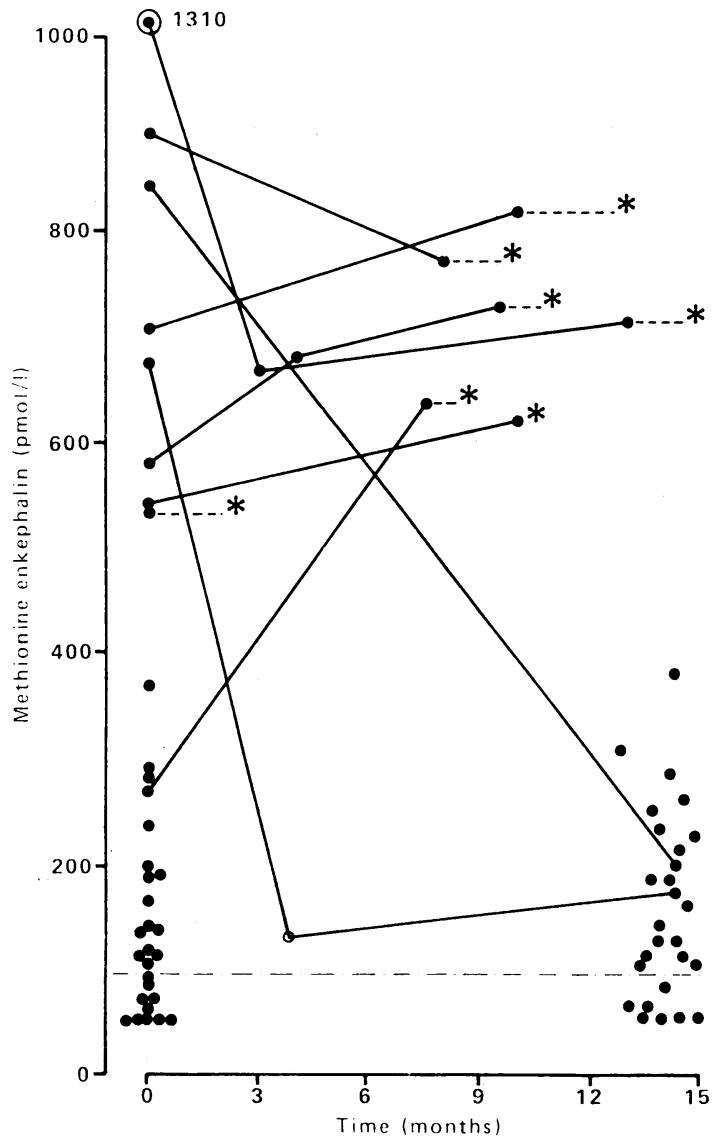

Plasma methionine enkephalin concentrations in patients with primary biliary cirrhosis. Horizontal dotted line indicates upper limit of normal in healthy controls

$\star$ Patient died 
diuretics; three from progressive cholestasis (two of whom had ascites only in their final weeks of life); and one from chronic hepatic encephalopathy (without ascites) and bronchopneumonia. Six of the eight patients with a very high initial plasma methionine enkephalin concentration $(530-1310 \mathrm{pmol} / \mathrm{l})$ died compared with only one of the 26 patients with lower initial concentrations $(50-365 \mathrm{pmol} / \mathrm{l} ; \mathrm{p}<0.001$, Fisher's exact test). In the six patients with a high initial concentration who died the concentration remained over $500 \mathrm{pmol} / 1(\mathrm{p}<0.05)$ whereas in the two who survived it fell to less than $200 \mathrm{pmol} / \mathrm{l}$. The two survivors had ascites when initially tested. They responded well to diuretics and remained free of fluid overload.

\section{Comment}

Plasma methionine enkephalin concentration correlated strongly with plasma bilirubin concentration (the best available biochemical marker of severity in primary biliary cirrhosis ${ }^{2}$ ) and also correlated with alkaline phosphatase activity and plasma albumin concentration. Thus the methionine enkephalin concentration reflects the severity of the disease, and a high concentration, particularly if sustained, indicates a poor prognosis.
Advanced primary biliary cirrhosis is an important indication for liver transplantation. ${ }^{4}$ Optimum timing of this operation is difficult. ${ }^{5}$ Although a progressive rise in plasma bilirubin concentration is a useful guide to the need for transplantation, it does not occur in all cases (three of our patients died with a plasma bilirubin concentration below $100 \mu \mathrm{mol} / \mathrm{l}$ ). All seven of our patients who died, however, had a plasma methionine enkephalin concentration greater than $500 \mathrm{pmol} / 1$, and in six of them this was present a median of 10 months before death. This suggests that the plasma concentration of this peptide should be investigated further as a guide to the prognosis of primary biliary cirrhosis and to the timing of liver transplantation.

We thank Dr A D Clayden of the department of community medicine, University of Leeds, for statistical advice.

1 Thornton JR, Dean H, Losowsky MS. Is ascites caused by impaired hepatic inactivation of blood-borne endogenous opioid peptides? Gut 1988;29: $1167-72$.

2 Shapiro JM, Smith H, Schaffner F. Serum bilirubin: a prognostic factor in primary biliary cirrhosis. Gut 1979;20:137-40.

3 Christensen E, Neuberger J, Crowe J, et al. Beneficial effect of azathioprine and prediction of prognosis in primary biliary cirrhosis. Gastroenterology 1985;89: 1084-91.

4 Bismuth H, Castaing D, Ericzon BB, et al. Hepatic transplantation in Europe. First report of the European Liver Transplant Registry. Lancet 1987;ii:674-6. 5 Hobbs KEF. Liver transplantation. A review. I Hepatol 1987;4:148-53.

(Accepted 19 July 1988)
Regional Department of Infectious Diseases and Tropical Medicine, Monsall Hospital, Manchester M10 8WR B K Mandal, FRCP, consultant physician

\section{Department of} Microbiology, Monsall Hospital

J Brennand, FIMLS, chief medical laboratory scientific officer

Correspondence to: Dr Mandal.

\section{Bacteraemia in salmonellosis: a 15 year retrospective study from a regional infectious diseases unit}

\section{B K Mandal, J Brennand}

The incidence of bacteraemia in non-typhoid salmonellosis is difficult to determine as many cases are never investigated and many patients are not admitted to hospital. In hospitals blood is not generally taken for culture unless septicaemia is suspected. Two large surveys in the United States, which reported incidences of $4.9 \%^{1}$ and $2.9 \%$ (including enteric fever,${ }^{2}$ included patients managed in the community as well as in hospital. We present data from the regional infectious diseases unit in Manchester, where blood samples are cultured from all patients admitted with acute diarrhoea.

\section{Patients, methods, and results}

We analysed the laboratory records of 1742 patients admitted during the 15 years $1969-83$ with proved salmonella infections; 89 serotypes were found, of which 72 were identified. Salmonella typhi and $S$ paratyphi types $\mathrm{A}$ and $\mathrm{B}$ were found in 213 patients, in whom the rates of bacteraemia were $63 \%(100 / 158)$, $71 \%(12 / 17)$, and $18 \%(7 / 38)$ respectively, whereas the rate was only $8 \%(124 / 1529)$ in the group with non-typhoid salmonellosis. $S$ typhimurium was the commonest faecal and blood isolate, although the rate of bacteraemia associated with it $(7 \cdot 0 \%)$ ranked only tenth (table). Analysis of bacteraemia by age showed a rate of $4.3 \%$ in children aged $<1$; the rate changed little until age 40 but thereafter rose steadily to reach $17 \%$ in people aged $\geqslant 70$.

Clinical records were available for 67 patients with bacteraemia out of 966 with non-typhoid salmonellosis admitted during 1975-83. Seventeen of these died compared with 28 of the 899 patients without bacteraemia $(p<0.00001)$. Thirty six patients had fever and 18 had leucocytosis $\left(>14 \times 10^{\circ} / 1\right)$. Underlying conditions were identified in 39 patients: 17 had gastric disorders (surgery, pernicious anaemia, antiulcer treatment); three were taking corticosteroids; and 19, all elderly, had chronic conditions such as cardiorespiratory and cerebrovascular diseases and alcoholism.

Fifty nine patients presented with gastroenteritis. The illness was typhoidal in seven others, and four had focal manifestations (osteomyelitis, arthritis, lung abscess, and gluteal abscess; three also had acute diarrhoea). Thirty nine of the patients with gastroenteritis were aged $\geqslant 60$ (36 of whom had moderate to severe dehydration), and all 17 deaths were in that age group. Of the 20 younger patients, eight were similarly

Bacteraemia in relation to serotype and age of patient

\begin{tabular}{|c|c|c|}
\hline & No of patients & No (\%) with bacteraemia \\
\hline \multicolumn{3}{|c|}{ Rate according to serotype } \\
\hline $\begin{array}{l}\text { Serotypes: } \\
\text { S typhimurium } \\
\text { S agona } \\
\text { S virchow } \\
\text { S hadar } \\
\text { S enteritidis } \\
\text { S heidelberg } \\
\text { S stanley } \\
\text { S newport } \\
\text { S indiana } \\
\text { S infantis } \\
\text { S saint paul } \\
\text { S kedougou } \\
\text { S panama } \\
\text { S montevideo } \\
\text { S dublin }\end{array}$ & $\begin{array}{l}540 \\
130 \\
115 \\
74 \\
71 \\
69 \\
58 \\
38 \\
36 \\
32 \\
24 \\
23 \\
22 \\
15 \\
13\end{array}$ & $\begin{array}{r}38(7.0) \\
5(3.8) \\
19(16.5) \\
6(8.1) \\
1(1.4) \\
7(10 \cdot 1) \\
9(15.5) \\
5(13.2) \\
7(21.9) \\
1(4.2) \\
2(8.7) \\
3(13.6) \\
5(38.5)\end{array}$ \\
\hline \multicolumn{3}{|c|}{ Age specific rates } \\
\hline $\begin{array}{l}\text { Age (years): } \\
<1 \\
1- \\
5- \\
10- \\
20- \\
40- \\
60- \\
\geqslant 70\end{array}$ & $\begin{array}{r}230 \\
172 \\
66 \\
100 \\
356 \\
191 \\
114 \\
300\end{array}$ & $\begin{array}{rr}10 & (4 \cdot 3) \\
7 & (4 \cdot 1) \\
5 & (7 \cdot 6) \\
5 & (5 \cdot 0) \\
15 & (4 \cdot 2) \\
16 & (8 \cdot 4) \\
15 & (13 \cdot 2) \\
51(17 \cdot 0)\end{array}$ \\
\hline Total & 1529 & $124(8 \cdot 1)$ \\
\hline
\end{tabular}

^Fifteen most common isolates. 